\title{
Effects of metal-contaminated soils on the accumulation of heavy metals in gotu kola (Centella asiatica) and the potential health risks: a study in Peninsular Malaysia
}

\begin{abstract}
Centella asiatica is a commonly used medicinal plant in Malaysia. As heavy metal accumulation in medicinal plants which are highly consumed by human is a serious issue, thus the assessment of heavy metals in C. asiatica is important for the safety of consumers. In this study, the heavy metal accumulation in $\mathrm{C}$. asiatica and the potential health risks were investigated. Samples of C. asiatica and surface soils were collected from nine different sites around Peninsular Malaysia. The concentration of six heavy metals namely $\mathrm{Cd}, \mathrm{Cu}, \mathrm{Ni}, \mathrm{Fe}$, $\mathrm{Pb}$ and $\mathrm{Zn}$ were determined by air-acetylene flame atomic absorption spectrophotometer (AAS). The degree of anthropogenic influence was assessed by calculating the enrichment factor (EF) and index of geoaccumulation (Igeo). The heavy metal uptake into the plant was estimated through the calculation of translocation factor (TF), bioconcentration factor (BCF) and correlation study. Estimated daily intakes (EDI) and target hazard quotients (THQ) were used to determine the potential health risk of consuming $\mathrm{C}$. asiatica. The results showed that the overall surface soil was polluted by $\mathrm{Cd}, \mathrm{Cu}$ and $\mathrm{Pb}$, while the uptake of $\mathrm{Zn}$ and $\mathrm{Ni}$ by the plants was high. The value of EDI and THQ showed that the potential of Pb toxicity in $\mathrm{C}$. asiatica was high as well. As heavy metal accumulation was confirmed in C. asiatica, daily consumption of the plant derived from polluted sites in Malaysia was not recommended.
\end{abstract}

Keyword: Centella asiatica; Heavy metals; Potential health risks; Peninsular Malaysia 